\title{
ANÁLISE COMPARATIVA DA GERAÇÃO DE RESÍDUOS ENTRE O LIGHT STEEL FRAMING E A CONSTRUÇÃO CONVENCIONAL
}

\section{ARTIGO ORIGINAL}

SOUZA, Whadson Viana da Silva, SANTOS JÚNIOR, Edmilson², LIMA, Lívia Ramos $^{3}$

SOUZA, Whadson Viana da Silva. SANTOS JÚNIOR, Edmilson. LIMA, Lívia Ramos. Análise comparativa da geração de resíduos entre o light steel framing e a construção convencional. Revista Científica Multidisciplinar Núcleo do Conhecimento. Ano 06, Ed. 12, Vol. 08, pp. 49-68. Dezembro de 2021. ISSN: 24480959, Link de acesso: https://www.nucleodoconhecimento.com.br/engenhariacivil/construcao-convencional,

DOI:

10.32749/nucleodoconhecimento.com.br/engenharia-civil/construcao-convencional

\section{RESUMO}

Devido ao grande consumo de recursos naturais, elevado consumo de energia, poluição ambiental e geração de resíduos, a construção civil é classificada como uma atividade altamente desgastante para o meio ambiente. Tendo em vista que, no Brasil, são utilizadas técnicas tradicionais de construção que trazem consigo prejuízos financeiros e ambientais durante todo o processo de construção, o presente artigo, visa responder: seria possível encontrar uma via que vise reduzir os danos ambientais e que seja financeiramente viável? Neste contexto, abordaremos o light steel framing ( $L S F)$, que tem se apresentado como uma excelente alternativa nestes quesitos, servindo como contraponto direto aos sistemas convencionais amplamente utilizados. Portanto, esta pesquisa, feita a partir de estudos

\footnotetext{
${ }^{1}$ Acadêmico do curso de Engenharia Civil da Faculdade Independente do Nordeste - FAINOR. ORCID: https://orcid.org/0000-0002-0415-5152.

${ }^{2}$ Acadêmico do curso de Engenharia Civil da Faculdade Independente do Nordeste - FAINOR. ORCID: https://orcid.org/0000-0002-4063-0571.

${ }^{3}$ Orientadora. ORCID: https://orcid.org/0000-0001-8505-737X.
}

RC: 103611

Disponível em: https://www.nucleodoconhecimento.com.br/engenhariacivil/construcao-convencional 
bibliográficos, tem como objetivo principal comparar a geração de resíduos da construção civil (RCC), o light steel framing e as construções convencionais. A partir da análise feita, os resultados mostram que construções utilizando o método $L S F$, geram quantidades significativamente menores de resíduos quando comparadas com alvenaria convencional, possuindo também menor associação a impactos ambientais, sendo considerada uma prática menos agressiva e mais sustentável.

Palavras-chave: Sustentável, Light steel framing, Resíduos da construção civil.

\section{INTRODUÇÃO}

A construção civil é reconhecida como uma das atividades de maior importância para o desenvolvimento das cidades, entretanto, o processo de produção da indústria da construção civil causa impacto ao meio ambiente ao longo de toda a sua cadeia produtiva (MESQUITA, 2012). Dados publicados pela Associação Brasileira de Empresas de Limpeza Pública e Resíduos especiais (ABRELPE, 2015) informou que cerca de 79,9 milhões de toneladas de resíduos são gerados ao ano, onde 45 milhões são específicos da construção civil. Diante dessa problemática abordada no presente estudo, medidas mitigatórias devem ser adotadas (SANTOS, 2019).

Neste contexto, o presente artigo, tem como questão norteadora: seria possível encontrar uma via que reduza os danos ambientais, seja financeiramente viável e que possa abranger todos os desafios atualmente existentes na construção civil? Nessa perspectiva, modelos construtivos mais ecológicos e ambientalmente adequados devem ser amplamente implantados. O novo sistema construtivo light steel framing (LSF) também conhecido como sistema auto-portante de construção a seco em aço, faz parte do sistema de Construção Energitérmica Sustentável (CES). O LSF é empregado internacionalmente para definir o material construtivo que utiliza o aço galvanizado como principal elemento estrutural, gerando elementos de baixo peso (PEDROSO, 2014). Diante disso, apesar de ter sido introduzida no Brasil ainda na década de 90, segundo o Ministério das Cidades, esse sistema trata-se de algo 
inovador, visto que o $L S F$ incorpora uma nova ideia que produz um sensível avanço na tecnologia já existente (LIMA, 2013; VITOR, 2012).

O método light steel frame surgiu nos Estados Unidos da América por volta do século XIX, quando os americanos estavam conquistando os territórios. Nessa perspectiva, eles desenvolveram esse sistema para solucionar os problemas habitacionais de maneira prática, rápida, com baixo custo e fácil acesso aos materiais ali disponíveis (LIMA, 2013; VITOR, 2012). Nesse contexto, esse sistema é beneficiado por uma série de vantagens relativas à gestão construtiva e aos clientes. Esse modelo facilita o gerenciamento de toda a produção e controle de qualidade: materiais mais leves, fácil seleção do material, paredes ortogonais, as esquadrarias funcionam sem qualquer tipo de interferência, menor quantidade de sucata e resíduos. Essa diminuição pode causar impactos positivos diretos na operação dos canteiros, como a melhor organização e utilização de equipamentos de logística (OLIVIERI, 2011).

Em consonância, outros benefícios como os insumos industrializados fabricados sob normas de qualidade (repercutindo em melhor qualidade dos acabamentos), padronização/modulação de medidas, utilização de mão-de-obra especializada, maior área útil, redução do tempo da construção, proporcionando custos ainda mais vantajosos, quando se trata em tempo de obra, custo financeiro e antecipação de uso e receitas, além das melhorias no conforto térmico e acústico. Ambientalmente, o sistema também é superior por gerar menor quantidades de resíduos, menor consumo de energia na movimentação de materiais, e menor impacto na implantação da obra (MILAN, 2011).

Contudo, apesar das inúmeras qualidades citadas desse modelo inovador, as tradicionais alvenarias em blocos de concreto ou cerâmicos e revestimentos em argamassa, com lançamento manual ou mecânico ainda predominam no Brasil e promovem impactos ecológicos através da geração de resíduos de construção e demolição (OLIVIERI, 2017). Portanto, considerando o crescente desenvolvimento da Construção Civil e dos impactos causados pela geração de resíduos é de

RC: 103611

Disponível em: https://www.nucleodoconhecimento.com.br/engenhariacivil/construcao-convencional 
extrema importância abordar os aspectos relacionados ao impacto ambiental e os novos métodos reutilizáveis para minimizar esses inconvenientes.

A engenharia civil é uma área de crescente desenvolvimento socioeconômico, consumindo cerca de 20 a $50 \%$ dos recursos naturais, gerando, infelizmente, resíduos e impactos ao meio ambiente. Desse modo, muitos resíduos ficam expostos ao meio por um tempo prolongado causando grandes problemas ambientais, sociais e econômicos. Nesse contexto, é necessária uma política que minimize os danos causados pela indústria civil, desde o processo da produção dos materiais até mesmo na geração e descarte desses resíduos, visto que, embora a construção civil demande de inúmeros recursos naturais, esse desenvolvimento está atrelado ao crescimento populacional, desse modo é necessário que eles sejam minimizados e descartados de maneira adequada, sustentável e que exista uma gestão desses produtos (SANTOS, 2019). Sendo assim, visto que a engenharia civil é de suma importância para o desenvolvimento socioeconômico e que o crescimento populacional é uma realidade, faz-se necessário realizar um trabalho que descreva sobre a geração de resíduos da construção civil (RCC) com a finalidade de sensibilizar o profissional para se adequar a novas medidas construtivas, visando métodos mais ecológicos.

Definindo assim, como objetivo geral, comparar a geração de resíduos da construção civil (RCC) entre o light steel framing e as construções convencionais.

Para alcançar o objetivo geral deve-se, por meio de pesquisa bibliográfica qualitativa descritiva, relatar os impactos sociais e ambientais da geração de resíduos da construção civil, analisar as leis e normas regulamentadas para a geração e descarte adequado dos RCC e descrever sobre o reaproveitamento dos resíduos de concreto em relação ao sistema construtivo light steel frame.

RC: 103611

Disponível em: https://www.nucleodoconhecimento.com.br/engenhariacivil/construcao-convencional 


\section{FUNDAMENTAÇÃO TEÓRICA}

Os resíduos de construção civil (RCC), segundo o Art. 13 da Lei 12.305/2010 são aqueles gerados nas construções, reformas, reparos e em demolições de obras, bem como da preparação e escavação de terrenos para obras civis. Estima-se que um valor médio de 0,50 t por habitante de RCC é gerado anualmente em algumas cidades brasileiras. Contudo, ainda existe grande dificuldade de se estabelecer estimativas de geração, tratamento e disposição exata em níveis estaduais, municipais e nacionais (LEITE, 2017). O relatório da Associação Brasileira de Empresas de Limpeza Pública e Resíduos Especiais mostra que, no Brasil, foram coletados 122.262 ton/dia de resíduos em 2014. Isso representa um indicador de $0,603 \mathrm{~kg} / \mathrm{hab}$.dia. (ASSOCIAÇÃO BRASILEIRA DE EMPRESAS DE LIMPEZA PÚBLICA E RESÍDUOS ESPECIAIS, 2014)

Nesse contexto, o processo de expansão dos países em desenvolvimento leva à um aumento das necessidades dos processos construtivos (LEITE, 2017), a construção civil é um dos mais importantes setores da economia, principalmente, para o crescimento do país. Esse setor se destaca na área produtiva, entretanto, o excesso de resíduos gerados pelo crescimento demográfico descontrolado e o aumento da renda causam impacto na quantidade de resíduos gerados (LEITE, 2017; SANTOS, 2019).

O entulho produzido geralmente é volumoso e inerte, ou seja, permanece por tempo prolongado na natureza, entretanto, possui um baixo nível de periculosidade quando comparados aos resíduos hospitalares, radioativos etc. (SANTOS, 2019). Entretanto, devido ao período de exposição prolongado, eles afetam o ambiente de diversas formas: poluindo o solo, a água e 0 ar, alteram o ambiente natural, entre outras degradações do ecossistema (BRAVO, 2019). A Resolução do Conselho Nacional do Meio Ambiente (CONAMA) classifica esses RCC em quatro classes:

Classe A: resíduos reutilizáveis ou recicláveis como agregados (referentes à construção); 
Classe B: resíduos recicláveis para destinações como plástico, papelão, gesso, metais e outros;

Classe C: resíduos onde não foram desenvolvidas tecnologias ou aplicações economicamente viáveis que permitam reciclagem/reutilização.

Classe D: resíduos perigosos oriundos do processo de construção (tintas, solventes, lâmpadas fluorescentes etc.) (MACIEL, 2016).

Observa-se que a geração dos RCC está atrelada ao crescimento e desenvolvimento das cidades, Segundo Lima (2012), em Fortaleza, 93,40\% dos RCC são classificados como resíduos de Classe A, sendo eles: $24,60 \%$ de areia e solo, $22 \%$ de argamassa, $15,60 \%$ de concreto, $14,30 \%$ de cerâmica vermelha, $10,40 \%$ de tijolo branco e outros. Nessa perspectiva, visando o crescente acúmulo e despejo desses materiais é comum a disposição irregular de entulho, sendo considerados como um problema de limpeza pública, acarretando uma série de inconvenientes como altos custos para o sistema de limpeza urbana, saúde pública, contaminação de solo, erosão, obstrução de sistemas de drenagem urbanos, assoreamento e contaminação de cursos d'água. Diante da problemática elucidada, faz-se necessário abordar com exatidão sobre os resíduos de concreto, suas implicações e os novos modelos recicláveis.

\subsection{RESÍDUOS DE CONCRETO}

A geração dos resíduos de construção e demolição variam conforme o tipo de obra e, consequentemente, as suas composições diferem de acordo com o que é empregado em cada cidade, sendo assim, observa-se divergências nas composições dos resíduos nas diversas cidades do país. O principal resíduo gerado na cidade de Porto Alegre - RS (2007) foi a argamassa (44,2\%), o concreto correspondeu a 18,3\% dos dejetos dessa cidade. Em São Leopoldo-RS e Novo Hamburgo-RS os resíduos de concreto atingiram $26 \%$ e 26,8\%, respectivamente (GONÇALVES, 2011). O concreto está entre os principais RCC quando falamos em 
trabalhos rodoviários (48\%) e sobras de demolição (58,3\%) (GONÇALVES, 2011). Em consonância, Mesquita (2012), exemplifica em seu estudo que as perdas de concreto chegaram a $123,3 \mathrm{~kg}$, o que corresponde a um percentual de $1,65 \%$ de 90 L trabalhados na pesquisa (MESQUITA, 2012).

O bloco de concreto é um material resistente, duradouro, dispensa revestimento e possui como principais componentes o cimento e a brita. $\mathrm{O}$ desperdício causado pelas quebras do material é menor quando comparado aos blocos de cerâmica. Em paredes estruturais ele pode ser utilizado em edifício com até 25 andares e em paredes de vedação não há um limite para a sua utilização. Sendo assim, suas construções detêm de aplicações funcionais para vedação, estrutural, térmica e acústica (PINHEIRO, 2018; ROSSI, 2017).

O bloco de concreto por se constituir de um material poroso, não possui um bom isolamento acústico e térmico, sendo suscetível a variações volumétricas em função da humidade e das variações térmicas. Frente a oscilações da temperatura, os materiais constituintes das alvenarias apresentarão diferentes variações dimensionais (PINHEIRO, 2018; ROSSI, 2017). Nesse contexto, por apresentar inúmeros benefícios para a construção civil, os blocos de concreto são utilizados em larga escala, devido a isso, os resíduos de concreto produzidos na concretagem são elevados.

Nessa perspectiva, entender que as políticas de gerenciamento têm por intuito assegurar a correta gestão dos RCC durante as atividades das obras e serviços de engenharia, se fundamentando nas estratégias de não geração, minimização, reutilização, reciclagem e descarte adequado (SANTOS, 2019). Sendo assim, primeiramente é de suma importância compreender as políticas de não geração, minimização e descarte adequado disponibilizadas nas normas e leis descritas a seguir.

RC: 103611

Disponível em: https://www.nucleodoconhecimento.com.br/engenhariacivil/construcao-convencional 


\subsection{LEIS E NORMAS QUE REGULAMENTAM OS RCC}

O CONAMA, como já mencionado, foi criado em 2002 com a finalidade de estabelecer a responsabilidade dos municípios, a criação, implementação e acompanhamento das diretrizes especificadas nos decretos municipais referente à gestão dos RCC. (CONAMA, 307/2002) Em consonância, os municípios são responsáveis por elaborar um programa municipal de gerenciamento de RCC com procedimentos e diretrizes técnicas que devem ser adotados no exercício das responsabilidades dos pequenos gerados e seus transportadores. (MATTOS, 2013)

De acordo com o CONAMA 307/2002, os resíduos não podem ser dispostos em aterros de resíduos sólidos urbanos, encostas, corpos d'água, lotes e áreas protegidas por lei. Os resíduos devem ser destinados de acordo com o artigo $10 \mathrm{da}$ resolução (CONAMA, 307/2002). Sendo assim, cabe ao Município elaborar e implementar Projetos de Gerenciamento de RCC e demolição que possam orientar, disciplinar e expressar os procedimentos necessários para o manejo e destinação ambientalmente adequados dos resíduos. (MATTOS, 2013)

Nessa perspectiva, o artigo 5 da resolução do CONAMA 307/2002 ainda traz que o plano municipal de gestão de resíduos da construção civil é um instrumento para a implementação da gestão dos resíduos e deve ser elaborado pelos municípios e pelo Distrito Federal, em consonância com o plano municipal de gestão integrada de resíduos sólidos. (CONAMA 307/2002).

Algumas normas também foram incrementadas para a resolução dessa problemática, serão citadas a NBR 15112: 2004 e a NBR 15113: 2004. A primeira, referente aos RCC e resíduos volumosos, tem importante papel na logística da destinação dos resíduos para áreas de transbordo e triagem, através de diretrizes para projetos e implantação e operação, possibilitando o recebimento de resíduos para posterior triagem e valorização. Contudo, a segunda norma relacionada aos RCC sólidos e resíduos inertes (aterros) promoveram diretrizes para projeto de implantação e operação, considerando critérios para a preservação dos materiais 
para o uso futuro ou disposição adequada para o aproveitamento posterior. (MATTOS, 2017)

Entretanto, mesmo diante das normas para o manejo adequado desses resíduos, a disposição irregular é um fenômeno internacional e no Brasil tem importante efeito na qualidade ambiental urbana e nos custos das prefeituras. Essa inadequada disposição na malha urbana tem sido relacionada com enchentes, assoreamento de córregos, prejuízos à paisagem, obstrução de vias de tráfegos e proliferação de doenças (DONATO, 2017).

Nessa perspectiva, a utilização dos resíduos de construção e demolição na fabricação de blocos de concreto e argamassas de assentamento é viável tecnicamente, podendo ser utilizado na construção de habitação e até mesmo em pavimentação de novas vias. Diante disso, elucidar as estratégias de reutilização e reciclagem dos novos modelos construtivos é imprescindível.

\subsection{REAPROVEITAMENTO DOS RESÍDUOS DE CONCRETO}

Os resíduos de concreto caracterizam-se por dejetos oriundos da demolição de estruturas de concreto, de usinas de concreto pré-misturado, fábricas de elementos pré-moldados e pavimentos de concreto (BRASILEIRO, 2015). A sua reutilização é denominada como agregados de concreto, e para que ocorra essa transformação é necessário que seja realizado o processo de beneficiamento. Nessa perspectiva, uma das maiores dificuldades relacionadas à reciclagem desses resíduos refere-se à separação eficiente das demais fases (argamassa, cerâmica, madeira, etc.) (BRASILEIRO, 2015). Para que ocorra essa segregação, algumas etapas são necessárias: cominuirão, separação, concentração e, por fim, operações auxiliares como transporte, secagem e homogeneização (GONÇALVES, 2012). Visto que esse processo demanda inovação, energia, tecnologia e tempo, esse processo acaba gerando altos custos e sendo dispendioso para as empresas (MESQUITA, 2012; ARAÚJO, 2016; BRANCO, 2012; BRASILEIRO, 2015; GONÇALVES, 2012).

RC: 103611

Disponível em: https://www.nucleodoconhecimento.com.br/engenhariacivil/construcao-convencional 
Ao se analisar as propriedades do concreto reciclado, observa-se: maior porosidade, maior absorção (que tende a aumentar com a incorporação dos agregados reciclados), baixa densidade e menores resistências, quando comparados com concretos convencionais (BRASILEIRO, 2015; LINTZ, 2012). Contudo, apesar da resistência à compressão dos agregados de concreto e a sua tração possuir uma redução de $10 \%$, os valores correspondem aos limites das normas brasileiras, mostrando que é possível a sua substituição e utilização como elemento de alvenaria (LINTZ, 2012; BRASILEIRO, 2015; MESQUITA, 2012; ARAÚJO, 2016; BRANCO, 2012; LIMA, 2013; GONÇALVES, 2011).

Diante disso, além das inúmeras Leis e Normas regulamentadas para minimizar a geração dos resíduos e gerenciá-las, falta a prática em implementar na Gestão Pública as medidas preconizadas. Em algumas capitais brasileiras, prefeituras já utilizam os resíduos reciclados para reestruturação de vilas habitacionais de baixa renda, obras de manutenção de instalações de limpeza urbana, pavimentações e outras obras públicas (BRASILEIRO, 2015). Diante disso é necessário que a população se conscientize: (1) da importância da Construção Civil para o desenvolvimento económico-social do país; (2) da estreita relação entre o crescimento urbano com o aumento da quantidade de resíduos; (3) impossibilidade de parar o processo de desenvolvimento do país e da adequação de medidas ambientalmente adequadas para que o país permaneça em crescimento. Sendo assim, é necessário que haja políticas públicas de comunicação, campanhas e iniciativas práticas por parte da gestão.

\subsection{O SISTEMA CONSTRUTIVO LIGHT STEEL FRAMING}

O LSF é um sistema construtivo de caracterização racional, contendo em seu modelo estruturas constituídas por perfis conformados a frio de aço galvanizado que são utilizados para produzir painéis estruturais e não estruturais (MILAN, 2011). Ao final da segunda guerra mundial, o aço era o material mais abundante e através dele, os países obtiveram grandes avanços, surgindo assim essa nova metodologia construtiva (PEDROSO, 2014). Diante disso, o Brasil introduziu essa nova técnica

RC: 103611

Disponível em: https://www.nucleodoconhecimento.com.br/engenhariacivil/construcao-convencional 
durante o ano de 1998, mostrando novas tendências tecnológicas no modo de construir. Esse modelo de construção veio como uma forma de atender as necessidades de uma sociedade em relação à construção civil (PEDROSO, 2014; MILAN, 2011; LIMA, 2013).

Por ser um método de construção civil prático diferente da alvenaria, que demonstra de forma exaustiva todas as vantagens e desvantagens de obra, tendo em vista o menor tempo de entrega da obra, melhor qualidade nos acabamentos, maior área útil (parede de menor espessura), melhorias no conforto térmico e acústico, além disso, os desvios de material, a mão de obra, a flexibilidade e o custo (PEDROSO, 2014). Ambientalmente, o sistema também é superior por produzir uma quantidade reduzida de resíduos, consumir menos energia devido a menor movimentação de materiais e menor impacto na implantação da obra (MILAN, 2011).

Apesar das inúmeras vantagens abordadas, algumas problemáticas devem ser levantadas, o LSF é conhecido como um sistema construtivo leve, caracterizado por sua baixa resistência ao fogo, o que pode ser melhorado com a utilização de materiais específicos. O comportamento deste tipo de sistema está ligado a diversos parâmetros, principalmente na sua configuração e/ou tipo de painel, aspectos geométricos e taxa de carregamento aplicada, o que torna mais difícil compreender o seu real comportamento em situação de incêndio (BOLINA, 2017). Além disso, a mão de obra é um dos problemas apresentados na difusão do sistema no Brasil, pois, para a sua execução é necessário que haja um treinamento e entendimento de uma série de etapas de montagem pelos operários da construção civil (CAMPOS, 2014).

O baixo nível de detalhamento do produto contraria o que é exigido pelo mercado da arquitetura, engenharia e construção, podendo ocasionar falhas na montagem e problemas futuros. A aceitação cultural é um fator determinante para a pouca difusão desse sistema no Brasil. Quanto ao custo do empreendimento, em função da maioria dos fornecedores e da mão de obra especializada ainda estarem na região sudeste, os custos empregados em fretes e deslocamentos de funcionários pode

RC: 103611

Disponível em: https://www.nucleodoconhecimento.com.br/engenhariacivil/construcao-convencional 
inviabilizar o uso do sistema em construções autônomas, entretanto, em construções comerciais o emprego do LSF tem avançado, pois possibilita uma obra rápida, o que justifica a sua utilização para os empreendedores (CAMPOS, 2014).

Nesse contexto, mesmo diante de empecilhos, o sistema construtivo light steel framing proporciona uma construção com menos impacto no meio ambiente, sendo uma construção mais sustentável e ecológica. Uma civilização é sustentável quando detém a capacidade de resistência e conservação por várias gerações - isso acontece através de uma combinação de longo prazo que cessa a deterioração dos recursos naturais. Ecologicamente falando, as construções com maior vida útil apresentam menor demanda por reparos em um futuro próximo e tende a demorar mais para ser convertido em resíduos, diminuindo o volume de materiais envolvidos (GURGULINO, 2017).

A análise ecológica é baseada no consumo de água, na poluição no processo de fabricação, adoção de materiais não renováveis e dinâmica dos resíduos. No cenário LSF por se tratar de um método a seco, o sistema construtivo gasta uma taxa muito menor de água no ciclo de vida, a água é aplicada apenas na fabricação de aço. Sendo assim, a fabricação de aço polui menos que o concreto, resultando em menos impacto (GURGULINO, 2017).

\section{PROCEDIMENTOS METODOLÓGICOS}

O presente estudo trata-se de uma pesquisa bibliográfica qualitativa descritiva e para sua operacionalização foram seguidas as seguintes etapas: seleção dos descritores, estabelecimentos dos critérios de seleção da amostra, representação das características da pesquisa original, análise dos dados, interpretação dos dados e apresentação da revisão. A busca foi realizada utilizando as bases de dados Scielo, Ethnoloque, CiteSeerX, BDTD, empregando uma combinação dos seguintes descritores, na língua inglesa: Wasting Generation AND Building AND Wast Management. A coleta de dados foi realizada entre os dias 01/08/2021 até 31/10/2021.

RC: 103611

Disponível em: https://www.nucleodoconhecimento.com.br/engenhariacivil/construcao-convencional 
Os critérios de inclusão são: a) artigos que analisam as gerações de resíduos na construção civil; b) trabalhos que descreveram as leis e normas para a gestão dos resíduos; c) estudos que relatam as consequências do descarte inadequado dos resíduos; d) período de publicação de 2011 a 2021.

Os critérios de exclusão são: a) publicações que não abordaram outros resíduos que não estão relacionados com a construção civil b) estudos que não descreviam a gestão de descarte desses resíduos; c) artigos publicados antes de 2011; d) publicações em outro idioma que não português ou inglês.

A seleção dos artigos foi realizada em etapas. Primeiro, foi feito a leitura dos títulos, resumos e conclusões dos estudos encontrados na pesquisa inicial, para aquelas obras em que mostrem evidências de não enquadramento para a revisão, serão automaticamente excluídas, e para aquelas as quais o título e o resumo não definam claramente sua inclusão, a leitura completa será realizada para avaliar sua inclusão ou não na revisão. Na sequência, será efetuado a leitura completa dos trabalhos escolhidos na primeira etapa, mediante aplicação de critérios de inclusão e exclusão supracitados. Foram coletados 60 artigos e apenas 28 foram selecionados para pesquisa.

\section{ANÁLISE DOS RESULTADOS}

Com base nos dados obtidos anteriormente, nesta seção serão discutidos os resultados, sendo feitas comparações entre as duas técnicas construtivas abordadas.

\subsection{COMPARAÇÃO DOS RESÍDUOS GERADOS}

Pelo fato do light steel framing ter uma estrutura com carga inferior à das construções convencionais, sua fundação é significativamente menor, sendo esta portanto a parte da construção que gera a maior quantidade de resíduos.

RC: 103611

Disponível em: https://www.nucleodoconhecimento.com.br/engenhariacivil/construcao-convencional 
De acordo com Holzmann (2017) em uma construção utilizando o método light steel framing há um comprometimento em cerca de $12,93 \%$ do montante total de materiais adquiridos para obra, que se tornarão RCC.

$\mathrm{Na}$ Tabela 1 percebe-se que as quantidades descartadas pela parte estrutural da obra geram cerca de $14,21 \%$ de RCC, quando comparada com perdas pela parede $(3,33 \%)$ e cobertura $(3,32 \%)$, chega a ser aproximadamente 4 vezes maior.

Tabela 1 - Resíduos por parte da edificação de LSF

\begin{tabular}{|c|c|c|c|c|c|c|c|}
\hline $\begin{array}{l}\text { APLI- } \\
\text { CAÇÄO }\end{array}$ & \multicolumn{2}{|c|}{ DESCRIÇÃO } & $\begin{array}{c}\text { QTDE } \\
\text { ADQUIRIDA } \\
(\mathrm{kg})\end{array}$ & $\begin{array}{c}\text { QTDE } \\
\text { APLICADA } \\
(\mathrm{kg})\end{array}$ & $\begin{array}{c}\text { QTDE } \\
\text { RESIDUO } \\
\text { (kg) }\end{array}$ & $\begin{array}{l}\text { PERDAS } \\
\text { POR } \\
\text { RCC (\%) }\end{array}$ & $\begin{array}{l}\% \text { DO } \\
\text { TOTAL }\end{array}$ \\
\hline \multirow{6}{*}{ 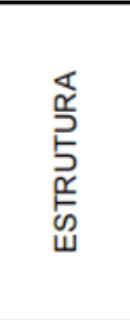 } & LASTRO & BRITA & \multirow{6}{*}{$42.730,24$} & \multirow{6}{*}{$37.621,33$} & \multirow{6}{*}{$5.345,16$} & \multirow{6}{*}{$14,21 \%$} & \multirow{6}{*}{$96,97 \%$} \\
\hline & FÔRMAS & $\begin{array}{l}\text { MADEIRA } \\
\text { SERRADA }\end{array}$ & & & & & \\
\hline & $\mathrm{AÇO}$ & $\mathrm{AÇO}$ & & & & & \\
\hline & \multirow{3}{*}{$\begin{array}{l}\text { CONCRETO } \\
\text { USINADO }\end{array}$} & CIMENTO & & & & & \\
\hline & & AREIA & & & & & \\
\hline & & BRITA & & & & & \\
\hline \multirow{5}{*}{ 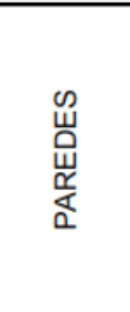 } & PERFIL DE AÇO & $\begin{array}{l}\text { AÇO } \\
\text { GALVANIZADO }\end{array}$ & \multirow{5}{*}{$3.285,80$} & \multirow{5}{*}{$3.179,99$} & \multirow{5}{*}{105,81} & \multirow{5}{*}{$3,33 \%$} & \multirow{5}{*}{$1,92 \%$} \\
\hline & $\begin{array}{l}\text { FECHAMENTO } \\
\text { EXTERNO }\end{array}$ & $\begin{array}{l}\text { PANEL H } \\
\text { SMARTSIDE }\end{array}$ & & & & & \\
\hline & \multirow{2}{*}{$\begin{array}{l}\text { FECHAMENTO } \\
\text { INTERNO }\end{array}$} & $\begin{array}{l}\text { GESSO } \\
\text { ACARTONADO }\end{array}$ & & & & & \\
\hline & & OSB & & & & & \\
\hline & ISOLAMENTO & LÃ DE VIDRO & & & & & \\
\hline \multirow{3}{*}{ 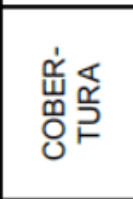 } & PERFIL DE AÇO & $\begin{array}{l}\text { AÇO } \\
\text { GALVANIZADO }\end{array}$ & \multirow{3}{*}{$1.902,93$} & \multirow{3}{*}{$1.841,71$} & \multirow{3}{*}{61,22} & \multirow{3}{*}{$3,32 \%$} & \multirow{3}{*}{$1,11 \%$} \\
\hline & SUBCOBERTURA & $\begin{array}{l}\text { OSB } \\
\text { TECHSHIELD }\end{array}$ & & & & & \\
\hline & COBERTURA & TELHA SHINGLE & & & & & \\
\hline \multicolumn{3}{|l|}{ TOTAL } & $47.918,96$ & $42.643,03$ & $5.512,18$ & $12,93 \%$ & $100,00 \%$ \\
\hline
\end{tabular}

Fonte: Holzmann (2017)

Já em comparação com uma construção convencional a quantidade de materiais utilizados é significativamente maior, porém o comprometimento desta totalidade que se tornará RCC excede a percentagem do light steel framing, chegando a comprometer cerca de $31,38 \%$ do montante total de materiais adquiridos para essa mesma obra.

RC: 103611

Disponível em: https://www.nucleodoconhecimento.com.br/engenhariacivil/construcao-convencional 
$\mathrm{Na}$ Tabela 2 percebe-se que as quantidades descartadas pela parte estrutural da obra geram cerca de $22,68 \%$ de RCC, quando comparada com perdas pela parede/revestimentos $(59,39 \%)$ e cobertura $(12,33 \%)$, observa-se que o quadro inverte drasticamente, sendo a etapa da parede/revestimentos responsável por mais que o dobro de RCC gerados pela estrutural.

Tabela 2 - Perdas por parte da edificação de alvenaria

\begin{tabular}{|c|c|c|c|c|c|c|c|}
\hline $\begin{array}{l}\text { APLI- } \\
\text { CAÇĀO }\end{array}$ & \multicolumn{2}{|c|}{ DESCRIÇÃO } & $\begin{array}{c}\text { QTDE } \\
\text { TEÓRICA } \\
\text { NECESSÁ- } \\
\text { RIA (kg) }\end{array}$ & $\begin{array}{l}\text { QTDE } \\
\text { PERDAS } \\
\text { POR RCC } \\
(\mathrm{kg})\end{array}$ & $\begin{array}{c}\text { QTDE } \\
\text { TOTAL (kg) }\end{array}$ & $\begin{array}{l}\text { PERDAS } \\
\text { POR } \\
\text { RCC (\%) }\end{array}$ & $\begin{array}{l}\text { \% DO } \\
\text { TOTAL }\end{array}$ \\
\hline \multirow{4}{*}{ 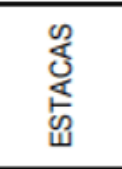 } & \multirow{3}{*}{ CONCRETO } & CIMENTO & \multirow{10}{*}{$83.123,683$} & \multirow{10}{*}{$18.849,945$} & \multirow{10}{*}{$97.745,019$} & \multirow{10}{*}{$22,68 \%$} & \multirow{10}{*}{$52,60 \%$} \\
\hline & & AREIA & & & & & \\
\hline & & BRITA & & & & & \\
\hline & ARMADURA & AÇO & & & & & \\
\hline \multirow{6}{*}{ 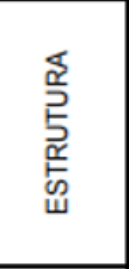 } & \multirow{3}{*}{ CONCRETO } & CIMENTO & & & & & \\
\hline & & AREIA & & & & & \\
\hline & & BRITA & & & & & \\
\hline & ARMADURA & $\mathrm{ACCO}$ & & & & & \\
\hline & \multirow{2}{*}{ FÔRMAS } & $\begin{array}{l}\text { MADEIRA } \\
\text { SERRADA }\end{array}$ & & & & & \\
\hline & & COMPENSADO & & & & & \\
\hline \multirow{3}{*}{$\begin{array}{l}\text { PARE- } \\
\text { DES }\end{array}$} & ALVENARIA & TIJOLO & \multirow{13}{*}{$27.954,530$} & \multirow{13}{*}{$16.601,150$} & \multirow{13}{*}{$44.555,680$} & \multirow{13}{*}{$59,39 \%$} & \multirow{13}{*}{$46,32 \%$} \\
\hline & \multirow{2}{*}{\begin{tabular}{|l|} 
ARGAMASSA DE \\
ASSENTAMENTO \\
\end{tabular}} & CIMENTO & & & & & \\
\hline & & AREIA & & & & & \\
\hline \multirow{10}{*}{ 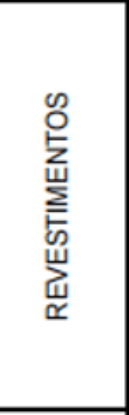 } & \multirow{2}{*}{ CHAPISCO } & CIMENTO & & & & & \\
\hline & & AREIA & & & & & \\
\hline & \multirow{3}{*}{$\begin{array}{l}\text { EMBOÇO } \\
\text { EXTERNO }\end{array}$} & CIMENTO & & & & & \\
\hline & & AREIA & & & & & \\
\hline & & CAL & & & & & \\
\hline & \multirow{3}{*}{\begin{tabular}{|l} 
EMBOÇO \\
INTERNO
\end{tabular}} & \begin{tabular}{|l|} 
CIMENTO \\
\end{tabular} & & & & & \\
\hline & & AREIA & & & & & \\
\hline & & CAL & & & & & \\
\hline & \multirow{2}{*}{ REBOCO } & AREIA & & & & & \\
\hline & & CAL & & & & & \\
\hline \multirow{2}{*}{$\begin{array}{l}\text { COBER- } \\
\text { TURA }\end{array}$} & MADEIRAMENTO & $\begin{array}{l}\text { MADEIRA } \\
\text { SERRADA }\end{array}$ & \multirow{2}{*}{$3.150,180$} & \multirow{2}{*}{388,278} & \multirow{2}{*}{$3.538,458$} & \multirow{2}{*}{$12,33 \%$} & \multirow{2}{*}{$1,08 \%$} \\
\hline & TELHAS & FIBROCIMENTO & & & & & \\
\hline \multicolumn{3}{|l|}{ TOTAL } & $114.228,393$ & $35.839,373$ & $145.839,157$ & $31,38 \%$ & $100,00 \%$ \\
\hline
\end{tabular}

Fonte: Holzmann (2017)

Já Jardim (2017) faz uma comparação da área construída à massa descartada de RCC utilizando o método construtivo light steel framing, onde, um projeto intitulado (Obra 1) com área construída de 491,47 $\mathrm{m}^{2}$ possui uma massa descartada de RCC de $510,82 \mathrm{Kg}$.

RC: 103611

Disponível em: https://www.nucleodoconhecimento.com.br/engenhariacivil/construcao-convencional 
Tabela 3 - Taxa de geração de RCC da obra 1

\begin{tabular}{c|c|c}
\hline $\begin{array}{c}\text { ÁREA } \\
\text { CONSTRUÍDA }\end{array}$ & MASSA & TAXA DE \\
$\left(\mathbf{m}^{2}\right)$ & DESCARTADA DE $(\mathbf{k g})$ & GERAÇÃO DE \\
\hline 491,47 & 510,82 & RCC $\left(\mathbf{k g} / \mathbf{m}^{2}\right)$ \\
\hline
\end{tabular}

Fonte: Jardim (2017)

Assim como no segundo projeto (Obra 2) com área de 15,28 $\mathrm{m}^{2}$ teve uma massa descartada de RCC de $60,54 \mathrm{Kg}$, o que gera uma taxa de geração de RCC significativamente maior $\left(3,96 \mathrm{~kg} / \mathrm{m}^{2}\right)$ quando comparada com a anterior $(1,04$ $\mathrm{kg} / \mathrm{m}^{2}$ ), apenas por reduzir a área construída. Devido as chapas de aço terem uma medida fixa na sua fabricação, a redução na área construída faz com que necessite de mais cortes nas barras de aço, gerando assim mais resíduos e uma taxa de geração mais elevada por $\mathrm{m}^{2}$.

Tabela 4 - Taxa de geração de RCC

\begin{tabular}{c|c|c}
\hline ÁREA CONSTRUÍDA & MASSA DESCARTADA DE & TAXA DE GERAÇÃODE \\
$\left(\mathrm{m}^{2}\right)$ & $\mathrm{RCC}(\mathrm{kg})$ & $\operatorname{RCC}\left(\mathrm{kg} / \mathrm{m}^{2}\right)$ \\
\hline 15,28 & 60,54 & 3,96 \\
\hline
\end{tabular}

Fonte: Jardim (2017)

Em consonância com os dados anteriores, uma pesquisa de campo realizada por Costa (2012) onde em 22 obras que utilizavam o método construtivo convencional 
REVISTA CIENTÍFICA MULTIDISCIPLINAR NÚCLEO DO

em alvenaria, na cidade de João Pessoa, tiveram uma média ponderada da taxa de geração de RCC de $93,89 \mathrm{Kg} / \mathrm{m}^{2}$.

A Tabela 5 faz uma comparação entre a área construída em metros quadrados com a massa descartada de RCC em quilogramas, a partir desta comparação tem-se a taxa de geração $\left(\mathrm{kg} / \mathrm{m}^{2}\right)$.

Tabela 5 - Relação das obras e taxa de geração de RCC.

\begin{tabular}{|l|l|l|l|}
\hline & $\begin{array}{l}\text { ÁREA } \\
\text { CONSTRUÍDA }\left(\mathrm{m}^{2}\right)\end{array}$ & $\begin{array}{l}\text { MASSA DESCARTADA DE } \\
\text { RCC }(\mathrm{kg})\end{array}$ & $\begin{array}{l}\text { TAXA DE GERAÇÃO } \\
\left(\mathrm{kg} / \mathrm{m}^{2}\right)\end{array}$ \\
\hline $\mathbf{1}$ & 985,50 & $99.425,00$ & 100,89 \\
\hline $\mathbf{2}$ & $43.858,80$ & $3.950 .862,50$ & 90,08 \\
\hline $\mathbf{3}$ & $16.976,51$ & $1.553 .387,50$ & 91,50 \\
\hline $\mathbf{4}$ & $1.250,00$ & $123.000,00$ & 98,40 \\
\hline $\mathbf{5}$ & 950,00 & $102.500,00$ & 107,89 \\
\hline $\mathbf{6}$ & $1.780,00$ & $143.500,00$ & 80,62 \\
\hline $\mathbf{7}$ & $1.949,00$ & $184.500,00$ & 94,66 \\
\hline $\mathbf{8}$ & $1.194,50$ & $147.600,00$ & 123,57 \\
\hline $\mathbf{9}$ & 998,00 & $107.625,00$ & 107,84 \\
\hline $\mathbf{1 0}$ & 70,00 & $10.250,00$ & 146,43 \\
\hline $\mathbf{1 1}$ & 95,00 & $10.762,50$ & 113,29 \\
\hline $\mathbf{1 2}$ & 150,00 & $11.275,00$ & 75,17 \\
\hline $\mathbf{1 3}$ & $2.299,02$ & $208.177,50$ & 90,55 \\
\hline $\mathbf{1 4}$ & 997,64 & $169.586,25$ & 169,99 \\
\hline $\mathbf{1 5}$ & 840,00 & $73.800,00$ & 87,86 \\
\hline $\mathbf{1 6}$ & 445,56 & $49.712,50$ & 111,57 \\
\hline $\mathbf{1 7}$ & 232,45 & $36.900,00$ & 158,74 \\
\hline $\mathbf{1 8}$ & 394,30 & $36.462,50$ & 100,08 \\
\hline $\mathbf{1 9}$ & 754,93 & $78.412,50$ & 103,87 \\
\hline & & & \\
\hline
\end{tabular}

RC: 103611

Disponível em: https://www.nucleodoconhecimento.com.br/engenhariacivil/construcao-convencional 


\begin{tabular}{|l|l|l|l|}
\hline $\mathbf{2 0}$ & $4.997,00$ & $521.007,50$ & 104,26 \\
\hline $\mathbf{2 1}$ & 455,40 & $40.487,50$ & 88,91 \\
\hline $\mathbf{2 2}$ & $1.031,80$ & $102.910,00$ & 99,74 \\
\hline MÉDIA PONDERADA & & $\mathbf{9 3 , 8 9}$ \\
\cline { 2 - 4 }
\end{tabular}

Fonte: Costa (2012)

Em uma comparação feita por Jardim (2017) utilizando a taxa de geração de RCC em alvenaria $\left(93,89 \mathrm{Kg} / \mathrm{m}^{2}\right) \mathrm{com}$ a taxa de geração de $\mathrm{RCC}$ do light steel frame $(1,13$ $\left.\mathrm{kg} / \mathrm{m}^{2}\right)$, tem-se uma diferença significativamente alta de $92,76 \mathrm{~kg} / \mathrm{m}^{2}$ de obra.

No Gráfico 3 nota-se a diferença significativa entre os dois métodos construtivos, onde o light steel framing não chega a alcançar os $5 \mathrm{~kg} / \mathrm{m}^{2}$ de RCC, ao contrário do que indica as construções convencionais, que chega a quase $94 \mathrm{~kg} / \mathrm{m}^{2}$.

Gráfico 3 - Comparação da taxa de geração de RCC $\left(\mathrm{kg} / \mathrm{m}^{2}\right)$ dos sistemas construtivos

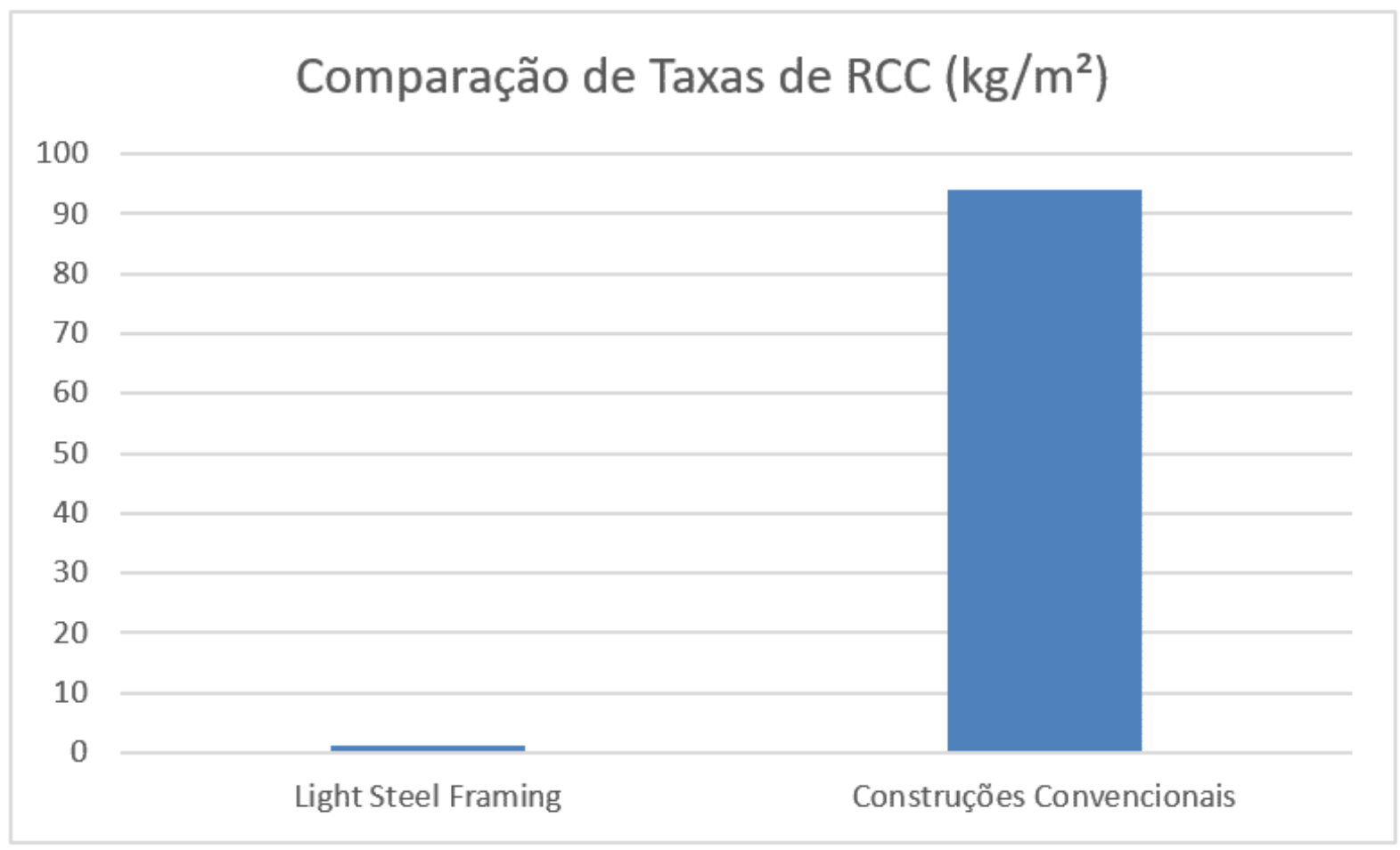

Fonte: Jardim (2017)

RC: 103611

Disponível em: https://www.nucleodoconhecimento.com.br/engenhariacivil/construcao-convencional 
Diante das propostas elucidadas, nota-se a diferença significativa entre os dois métodos construtivos, essa enorme discrepância tem impacto não só ambiental, como, também econômico, pois não se fará necessária a alocação de grandes áreas para instalação do canteiro de obras, assim como a retirada do entulho da obra será reduzida drasticamente.

\section{CONSIDERAÇÕES FINAIS}

Após ler, analisar, comparar e sintetizar diversos autores a respeito do tema, concluímos que é notória a diferença entre os dois métodos construtivos, onde, optar pelo menor impacto ambiental não significa apenas zelar pela natureza, mas também gerar um ambiente de trabalho saudável, organizado, econômico e, certamente, mais seguro para todos.

Optar por alternativas que trilhe a favor da sustentabilidade, além de favorecer as próximas gerações, valoriza não só a construção em si, como também o profissional por traz dela, gerando então um ciclo virtuoso no cenário da construção civil, algo necessário nas condições ambientais atuais. Portanto, retomando a questão norteadora: seria possível encontrar uma via que vise reduzir os danos ambientais e que seja financeiramente viável? Constatamos que o light steel framing é um método capaz de gerar construções econômicas, sustentáveis e altamente adaptáveis. Alcançando assim os nossos objetivos e expectativas a respeito do tema, sendo suficientemente abrangente o método utilizado para realização dos procedimentos.

\section{REFERÊNCIAS}

ARAÚJO, D. L.; FELIX, L. P.; SILVA, L. C.; SANTOS, T. M. Influência de agregados reciclados de resíduos de construção nas propriedades mecânicas do concreto. REEC, v. 11, n. 1, p. 16-33, 2016. 
BOLINA, F.; CRISTO, R.; METZLER, A. et al. Comparação da resistência ao fogo de dois sistemas de paredes estruturais em estruturas de Light Steel Frame. DYNA, v. 84, n. 201, p. 123-128, 2017.

BRANCO, R. P. Utilização de resíduos de concreto em concreto autoadensável. 2012. 112f. Dissertação (Trabalho de Conclusão de Curso de Engenharia Civil) - Universidade Estadual Paulista, Ilha Solteira, 2012.

BRASILEIRO, L. L.; MATOS, J. M. E. Revisão bibliográfica: reutilização de resíduos da construção e demolição na indústria da construção civil. Cerâmica, v. 61 , p. 178-89, 2015.

BRAVO, J.; VALDERRAMA, C.; OSSIO, F. Cuantificación Económica de los resíduos de construcción de una edificación en altura: un caso de estudio. Información Tecnológica, v. 30, n. 2, 2019.

CAETANO, M. O.; FAGUNDES, A. B.; GOMES, L. P. Modelo de regressão linear para estimativa de geração de RCD em obras de alvenaria estrutural. Ambiente Construído, v. 18, n. 2, p. 309-324, 2018.

CAMPOS, P. Light Steel Framing: Uso em construções habitacionais empregados a modelagem virtual como processos de projeto e planejamento. 2014. 198f. Dissertação (Dissertação apresentada para a obtenção do título de Mestre em Arquitetura e Urbanismo) - Universidade de São Paulo, São Paulo, 2014.

CARDOSO, A. C. F.; GALATTO, S. L.; GUADAGNIN, M. R. Estimativa da geração de resíduos da construção civil e estudo de viabilidade de usina de triagem e reciclagem. Rev Bras Cienc Ambien, n. 31, 2014.

CARELI, E. D. A resolução CONAMA n' $307 / 2002$ e as novas condições para gestão dos resíduos de construção e demolição. Dissertação (Mestrado em Tecnologia) - Centro Estadual de Educação Tecnológica Paula Souza, São Paulo, 2008. 
COSTA, Ricardo Vasconcelos Gomes da; ATHAYDE JÚNIOR, Gilson Barbosa; OLIVEIRA, Mariana Moreira de. Taxa de geração de resíduos da construção civil em edificações na cidade de João Pessoa. Ambiente Construído, [S.L.], v. 14, n. 1, p. 127-137, mar. 2014. FapUNIFESP (SciELO). http://dx.doi.org/10.1590/s167886212014000100011. https://www.scielo.br/j/ac/a/QkC63LDYbbxpPkKQ7sKW7Sv/?lang=pt\#: :text=A\%20t axa\%20de\%20RCC\%20bruto,02\%20kg\%20m\%2D2\%20respectivamente.. Acesso em: 07 ago. 2021.

DONATO, C. J.; SILVA, I. C.; ASTOLPHI, J. L. L. et al. Reciclagem de resíduos da construção civil. Colloquium Humanarum, v. 14, n. especial, p. 666-70, 2017.

GONÇALVES, M. S. Análise da viabilidade técnica de utilização de resíduos de concreto oriundos da pré-fabricação como agregado graúdo para a produção de novos concretos. 2011. 118f. Dissertação (Programa de Pós-Graduação em Engenharia Civil) - Universidade do Vale do Rio dos Sinos, São Leopoldo, 2011.

GURGULINO, J.; SARAIVA, R.; TATIANA, M. Light Steel Framing and Structural Concrete Walls: Sustainbable Perspectives for Affordable Housing. European Journal of Ssustainable Development, v. 6, n.3, p. 483-490, 2017.

LEITE, I. C. A.; DAMASCENO, J. L. C.; REIS, A. M. et al. Gestão de resíduos na construção civil: um estudo em Belo Horizonte e região metropolitana. Revista Eletrônica de Engenharia Civil, v. 14, n. 1, 2018.

LIMA, A. S.; CABRAL, A. E. B. Caracterização e classificação dos resíduos de construção civil da cidade de Fortaleza. Eng Sanit Ambient, v. 18, n. 2, p. 169-76, 2013.

LIMA, R. F. Técnicas, métodos e processos de projeto e construção do sistema construtivo Light Steel Frame. 2013. 157f. Dissertação (Pós-Graduação em Construção Civil) - Universidade Federal de Minas Gerais, Belo Horizonte, 2013. 
LINTZ, R. C. C.; JACINTHO, A. E. P. G. A.; PIMENTEL, L. L.; GACHET-BARBOSA, L. A. Estudo do reaproveitamento de resíduos de construção em concretos empregados na fabricação de blocos. Ibracon, v. 5, n. 2, p. 166-181, 2012.

MASS, Bárbara Holzmann. Resíduos de construção civil na obra de uma edificação e seus impactos: estudo de caso de uma residência em Light Steel Framing e simulação de uma em alvenaria. Acervodigital da Ufpr, Curitiba, p. 31 94, 30 mar. 2017. Disponível em: https://acervodigital.ufpr.br/handle/1884/47702. Acesso em: 08 ago. 2021.

MESQUITA, A. S. G. Análise da geração de resíduos sólidos da construção civil em Teresina, Piauí. Holos, v. 2, p. 58-65, 2012.

MILAN, G. S.; NOVELLO, R. V.; REIS, Z. C. A viabilidade do Sistema Light Steel Frame para construções residenciais. Revista Gestão Industrial, v. 7, n. 1, 2011.

OLIVIERI, H.; BARBOSA, I. C. A.; ROCHA, A. C. et al. A utilização de novos sistemas construtivos para a redução no uso de insumos nos canteiros de obras: Light Steel Framing. Ambient. Constr., v. 17, n. 4, 2017.

PEDROSO, S. P.; FRANCO, G. A.; BASSO, G. L. et al. Steel frame na construção civil. Anais do $12^{\circ}$ Encontro Científico Cultural Interinstitucional, 2014

PEREIRA, S. S.; CURI, R. C.; CURI, W. F. Uso de indicadores na gestão dos resíduos sólidos urbanos: parte II - uma proposta metodológica de construção e análise para municípios e regiões: aplicação do modelo. Eng Sanit Ambient, v. 23, n. 3, p. 485-498, 2018.

PINHEIRO, G.S. Alvenaria estrutural em blocos de concreto: aspectos construtivos e pré-dimensionamento. Dissertação (Trabalho de Conclusão do Curso de Engenharia Civil) - Universidade Federal do Rio de Janeiro, Escola Politécnica, Rio de Janeiro, 2018. 
ROSSI, C.T. Análise técnica dos tijolos maciços e blocos cerâmicos de vedação 6 furos produzidos na região da Grande Santa Rosa - RS. 2017. 113f. Dissertação (Trabalho de Conclusão de Curso) - Universidade Regional do Noroeste do Estado do Rio Grande do Sul, Santa Rosa, 2017.

SANTOS, A. S.; ISELLE, F. A; DIAS-SILVA, L. H. Resíduos da Construção Civil: conceitos, histórico e gerenciamento. Rev. Eletrônica Organ. Soc., v. 8, n. 10, p. 5-21, 2019.

SANTOS, Liara Jardim. Light Steel Framing: Um estudo do método construtivo e análise da geração de resíduos nos canteiros de obra. 1 Library, [s. I], p. 23-119, 04 dez. 2017. Disponível em: https://1library.org/document/ydvpj8jy-steel-framingmetodo-construtivo-analise-geracao-residuos-canteiros.html. Acesso em: 09 set. 2021.

VITOR, R. O. Modelagem numérica de diagonais equivalentes em painéis de cisalhamento do Sistema Light Steel Framing. 2012. 131. Dissertação (PósGraduação em Engenharia de Estruturas) - Escola de Engenharia da Universidade de Minas Gerais, Belo Horizonte, 2012.

Enviado: Novembro, 2021.

Aprovado: Dezembro, 2021.

RC: 103611

Disponível em: https://www.nucleodoconhecimento.com.br/engenhariacivil/construcao-convencional 